EVS26

Los Angeles, California, May 6-9, 2012

\title{
Multifunctional Optimal Design of Axial-Flux Permanent Magnet Wheel Motors for Light Electric Vehicles
}

\author{
Yee-Pien Yang and Chung-Han Lee \\ Department of Mechanical Engineering, National Taiwan University, Taipei 106, Taiwan, ROC \\ ypyang@ntu.edu.tw
}

\begin{abstract}
This paper presents a systematic approach of optimal design for an axial-flux permanent magnet wheel motor to have high torque density for light electric vehicles. First, the winding type and the numbers of slots and poles are determined at the stage of preliminary design. A magnetic circuit model with an effective air-gap distribution is then established for sensitivity analysis and multifunctional optimization. Finally, the finite element analysis is performed for verifying and refining the motor with the best torque density to fulfill design specifications. The theory of maximum torque per ampere is also applied to estimate the torque and power versus speed curves of the resulting wheel motor before it is fabricated.
\end{abstract}

Keywords: Axial-flux permanent magnet wheel motor, electric vehicle, optimization

\section{Introduction}

Electric vehicles (EVs) have imperatively attracted quite a few researchers and automobile companies in developing more efficient and reliable propulsion systems, because of the increasing concerns about natural environment and growing shortages of petroleum resources [1]. However, traditional motors for the propulsion system of EVs had a stereotype of heavy weight, low output torque, and low efficiency. It has been an important issue to improve the motor performance in terms of efficiency and torque and power densities [2]. It is promising to drive an EV directly with wheel motors so that the powertrain does not need mechanical gearshifts or differentials, and the efficiency of the propulsion system must be increased.

Axial-flux permanent magnet (AFPM) motors usually have better torque and power densities than traditional radial-flux PM motors, and therefore are taken into consideration for driving a light EV (LEV) in this research. There are two major types of AFPM motor-Kaman type and Torus type. The main differences between these two types are the number and configuration of rotors and stators. A Kaman type motor has one rotor sandwiched by two stators, while a Torus type motor has two rotors to sandwich one stator. Due to the relative position of stators and rotors, the Kaman type has better heat dissipation property than the Torus type motor [3] [4].

This paper presents an optimal design of an AFPM wheel motor of Kaman type for an LEV. The preliminary design determines a set of initial design parameters with a zero-dimensional model for the subsequent optimal design. The optimal design is then performed with one-dimensional magnetic circuit model so that the torque, torque density and efficiency of the AFPM motor are maximized and the torque ripple is minimized, subject to a set of constraints. Finally the finite element analysis is used to verify and refine the final shape of the motor, and the performance curves are estimated before the fabrication of prototype. 


\section{Specifications}

The proposed wheel motor is designed for an LEV, whose specifications are illustrated in Table 1. For satisfying the requirement of high torque at low speed and low torque at high speed, it is necessary to propose an electric gearshift by changing the stator windings between serial and parallel connections. The objective torque for the first gear is therefore specified higher than 96 $\mathrm{Nm}$, and the ideal torque versus speed (T-N) curve is proposed in Fig. 1. The switching point between the first and the second gearshifts is chosen around $369 \mathrm{rpm}$, which is close to an operating speed of the LEV.

Table 1. Specifications of Wheel Motors for LEV

\begin{tabular}{|c|c|}
\hline Weight & $350 \mathrm{~kg}$ \\
\hline Tire rim & 15 'Al-alloy \\
\hline Rated voltage & 72 VDC \\
\hline Rated phase current & 19.8 Ampere \\
\hline Connection & 3 independent phases \\
\hline Max. power & $8 \mathrm{~kW}$ \\
\hline Torque & $96 \mathrm{Nm}(0-737 \mathrm{rpm})$ \\
\hline Heat dissipation & Air cooling \\
\hline
\end{tabular}

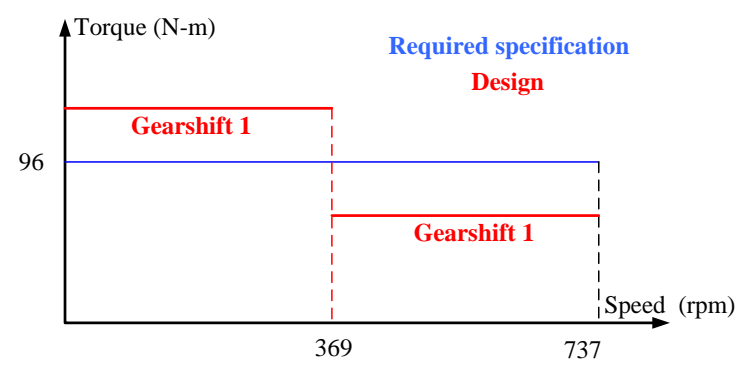

Figure 1: An ideal T-N curve of the wheel motor and its gearshift region

\section{Preliminary and Optimal Design}

A systematic approach starts from the preliminary design with a zero-dimensional model, where the numbers of slot and pole and the winding configuration are chosen. The multifunctional optimal design with one-dimensional magnetic circuit models is then performed to determine an optimal shape of the wheel motor. Finally, the wheel motor is verified and refined by the finite element analysis.

\subsection{Preliminary design}

Under the assumption of constant equivalent air gap length, the output torque can be expressed as [5]

$$
T=\frac{1}{4 \pi} K_{w} n_{l} N_{s} B_{g} A_{g} N I \cos \gamma
$$

where $K_{w}$ is the winding factor, $n_{l}$ is the number of winding layers, $N_{s}$ is the number of slots, $B_{g}$ is the air gap flux density, $A_{g}$ is the cross-sectional area of air gap, $N$ is the number of turns, $I$ is the peak value of phase current, and $\gamma$ is the angle between the current and back electromotive force (back EMF) vectors.

Base on (1), it is easy to understand that the output torque is proportion to the winding factor, which is the multiplication of pitch factor $K_{p}$ and distribution factor $K_{d}$. The definitions of these two factors are [5]:

$$
\begin{gathered}
K_{p}=\sin \left(n S_{c} \frac{\pi}{2} \frac{\tau_{s}}{\tau_{p}}\right) \\
K_{d}=\frac{N_{p h}}{N_{s}} \sum_{i=1}^{N_{s} / N_{p h}} \vec{E}_{i}
\end{gathered}
$$

where the integer $n$ is the order of harmonics, $S_{c}$ is the coil span, $N_{p h}$ is the number of phase, and $\vec{E}$ is the back EMF vector. According to (2) and (3) the winding factors of various numbers of poles and slots are obtained in Table 2, where the symbol means the invalid combination of slots and poles.

Table 2. Winding Factors for Three-Phase Motors

\begin{tabular}{|c|c|c|c|c|c|c|c|}
\hline $\mathrm{N}_{\mathrm{s}}$ & 12 & 14 & 16 & 20 & 22 & 24 & 26 \\
\hline 15 & - & 0.951 & 0.951 & 0.866 & 0.711 & - & 0.389 \\
\hline 18 & 0.866 & 0.902 & 0.945 & 0.945 & 0.902 & 0.866 & 0.735 \\
\hline 21 & - & 0.866 & 0.900 & 0.953 & 0.953 & - & 0.900 \\
\hline 24 & - & 0.753 & 0.866 & 0.933 & 0.953 & - & 0.953 \\
\hline
\end{tabular}

Since both slot and pole combinations of 21/20 and $21 / 22$ have unbalanced axial force, they are not considered for a wheel motor. Both 24/22 and 24/26 combinations have the highest winding factor 0.953 because of the fractional ratio between the slots and poles [6]. However, the motor with 24 slots and 26 magnets presents better performance, as shown in Table 3 , and therefore is selected for the following optimal design.

\subsection{Optimal design}

\subsubsection{Design variables}

First, the motor parameters are defined in Fig. 2. On the stator side, $d_{l}$ is the shoe depth of stator tooth, $d_{3}$ is the conductor slot depth, $w_{s s}$ is the width of winding, $w_{t b}$ is tooth width, $w_{s b}$ is the stator backiron width, $\tau_{s}$ is the slot pitch, $o$ is the slot opening, and the air gap $g$ is defined as the shortest distance between the stator teeth and 
magnet on rotor. On the rotor side, $w_{m}$ is the magnet width, $\tau_{m}$ is the pole pitch, and $l_{m}$ is the magnet length. In addition to geometric parameters, the winding diameter is denoted by $d_{w}$, the number of turns is defined as $N$, while the winding current is represented as $i$.

Table 3. Motor Performance of Preliminary Designs

\begin{tabular}{|c|c|c|}
\hline Slot/pole & $24 / 22$ & $24 / 26$ \\
\hline Torque average $(\mathrm{Nm})$ & 132.1 & 145.6 \\
\hline Torque ripple (\%) & 12 & 7.4 \\
\hline Weight $(\mathrm{kg})$ & 8.74 & 8.78 \\
\hline Torque density (Nm/kg) & 15.1 & 16.6 \\
\hline Back EMF peak (V @ 400rpm) & 69 & 70 \\
\hline Phase current (A) & 19.8 & 19.8 \\
\hline Turns & 18 & 18 \\
\hline Axial length (mm) & 45.5 & 46 \\
\hline Outer radius (mm) & 120 & 120 \\
\hline Magnet width (mm) & 0.86 & 0.87 \\
\hline Inner radius (mm) & 69 & 69 \\
\hline Air gap length (mm) & 0.5 & 0.5 \\
\hline Magnet thickness (mm) & 9.5 & 10 \\
\hline
\end{tabular}
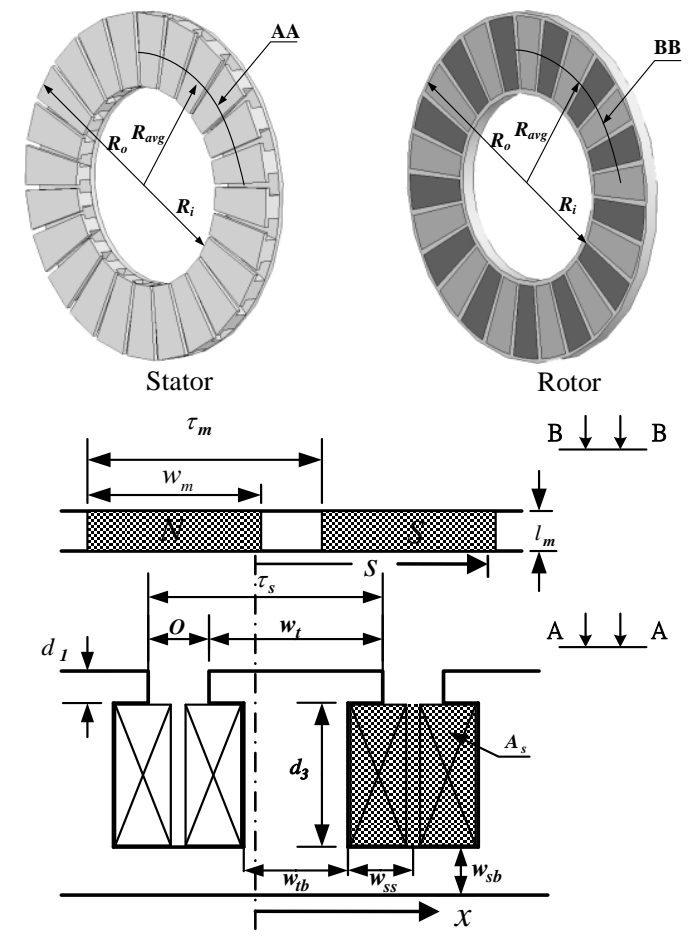

Fig. 2. Design variables on stator and rotor.

\subsubsection{Optimal design with magnetic circuit model}

When the peripheral coordinate $x$ is defined along the air gap on the stator, the rotor shift $s=\gamma R_{\text {avg }}$, where $\gamma$ is defined as the relative angular displacement of rotor. These two variables are used to describe the distribution functions of air gap length, magnetomotive force (MMF), and magnetic flux density.

Under the assumption of the linear operation range of magnetic flux density and magnetic field intensity, the total MMF $F(x, s)$ is a linear combination of the MMF of magnets and the MMF of stator windings

$$
F(x, s)=F_{r}(x, s)+F_{s}(x, s)
$$

Here,

$$
F_{r}(x, s)=H_{c} l_{m}
$$

and

$$
F_{s}(x, s)=N i
$$

where $H_{c}$ is the magnet coercivity. The total air gap $\delta(x, s)$ between the stator and rotor is represented by

$$
\delta(x, s)=\delta_{r}(x, s)+\delta_{e}(x, s)
$$

where $\delta_{r}(x, s)$ is the air gap on the rotor side, and $\delta_{e}(x, s)$ is the effective air gap on the stator side [7]. The magnetic coenergy is therefore written as

$$
W_{m g}^{\prime}(s)=\frac{\mu_{0}}{2}\left(R_{o}-R_{i}\right) \int \frac{F^{2}(x, s)}{\delta(x, s)} d x,
$$

and the torque production is derived by

$$
T(\gamma)=\left(\frac{\partial W_{m g}^{\prime}}{\partial \gamma}\right)_{\mathrm{i}=\text { constant }}
$$

Also, the back EMF can be derived by

$$
E=\omega \frac{d \lambda}{d \gamma}
$$

where $\lambda$ denotes the flux density, which is obtained by

$$
\lambda=\int N B_{g} d A .
$$

\subsubsection{Sensitivity analysis}

Sensitivity analysis is performed to choose the most influential design variables to the objective functions or performance indices that are minimized or maximized for the optimal shape of the motor. Motor performance is evaluated by four objectives:

Average torque

$$
T_{\text {avg }}=\text { average } T(\gamma)
$$

Torque ripple

$$
T_{p}=\frac{T_{\max }-T_{\min }}{T_{\text {avg }}} 100 \%
$$


Torque density

$$
T_{d}=\frac{T_{a v g}}{W}
$$

Efficiency

$$
\eta=\frac{T_{r} \omega_{r}}{T_{r} \omega_{r}+P_{r}+P_{c}+P_{s}}
$$

where $W$ is the motor weight, $\omega_{r}$ is the rated speed of motor, $T_{r}$ is the rated torque, $P_{r}$ is the copper loss, $P_{c}$ is the core loss, and $P_{s}$ is the friction loss, which is usually assumed as $5 \%$ of the output power during the analysis.

Sensitivity index is therefore defined as the ratio of the variation of motor performance to the variation of per unit (p.u.) design variable. It was found from Fig. 3 that the most influential design variables are the air gap length $g$, inner radius $R_{i}$, magnet length $l_{m}$, number of turns $N$, phase current $i_{\text {phase }}$, as well as the magnet width ratio $\alpha_{m}=w_{m} / \tau_{m}$, and the slot opening ratio $\alpha_{o}=o / \tau_{s}$.

\subsubsection{Multifunctional optimization}

The compromise programming method in the optimizer - multifunctional optimization system tool (MOST) [8] is used for searching the best set of design variables that maximize or minimize the four objectives (12)-(15), which are expressed implicitly or explicitly as functions of those design variables determined from sensitivity analysis.

In the optimization process, different weightings on the four objectives were assigned for their individual importance, as shown in Table 4. Among all the optimization results, only two best results were selected and compared with the initial design. For example, higher torque density was obtained from the case of weightings 1:5:10:1 than from 1:5:5:1, although the resulting weight of the motor differed little. Finally, it was the designer's decision to choose the result from the weighting 1:5:10:1 for its highest torque density and lowest weight. The corresponding torque distribution based on the 1D magnetic circuit model is shown in Fig. 4.

\section{Finite Element Analysis}

Finite element analysis is used to verify and refine the motor shape and performance from the one-dimensional design based on the magnetic circuit model. Here, the stator tooth is reshaped for a feasible manufacturing process, and the slots are skewed for reducing the cogging torque.
The direct $(d)$ and quadrature $(q)$ inductances are analysed to estimate the torque and power versus speed curves based on the theory of maximum torque per ampere (MTPA) [9]. Therefore, the best current angles are determined for driving the motor efficiently at different speeds.
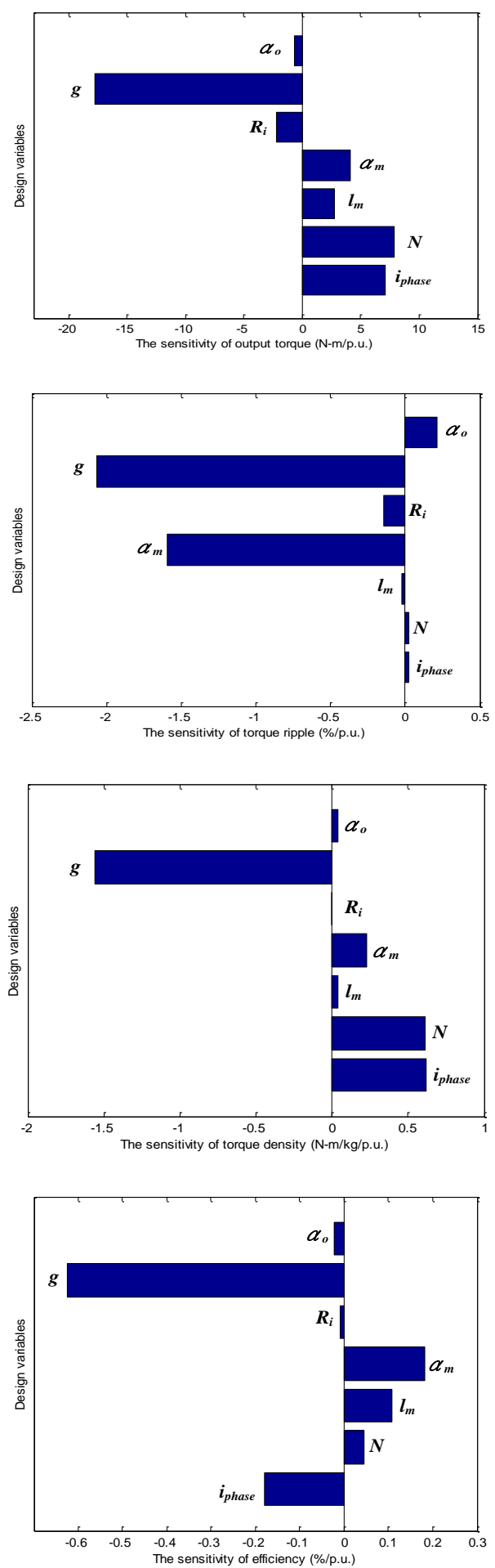

Fig. 3. Sensitivity index of (a) output torque (b) torque ripple (c) torque density (d) efficiency in terms of design variables. 
Table 4. Optimal Design Variables and Performances

\begin{tabular}{|c|c|c|c|}
\hline \multirow{2}{*}{$\begin{array}{l}\text { Weighting } \\
\text { Parameters }\end{array}$} & \multicolumn{3}{|c|}{$T_{a v g}: T_{p}: T_{d}: \eta$} \\
\hline & Initial & $1: 5: 5: 1$ & 1:5:10:1 \\
\hline$\alpha_{0}$ & 0.1 & 0.1 & 0.13 \\
\hline$(\mathrm{mm})$ & 1 & 0.65 & 0.5 \\
\hline$(\mathrm{mm})$ & 72 & 68 & 69 \\
\hline$\alpha_{m}$ & 0.88 & 0.88 & 0.87 \\
\hline$(\mathrm{mm})$ & 15 & 9 & 10 \\
\hline (turns) & 18 & 18 & 18 \\
\hline$i_{\text {phase }}$ & 19.8 & 19.8 & 19.8 \\
\hline$(\mathrm{kg})$ & 11.46 & 11.03 & 10.89 \\
\hline$P_{r} @ 90^{\circ} \mathrm{C} \quad(\mathrm{W})$ & 343 & 367 & 362 \\
\hline$P_{c} @ 400 \mathrm{rpm}(\mathrm{W})$ & 39 & 41 & 40 \\
\hline $\begin{array}{ll}T_{a v g} & (\mathrm{Nm})\end{array}$ & 141 & 146 & 145 \\
\hline$(\%)$ & 8.8 & 7.13 & 7.28 \\
\hline$(\mathrm{Nm} / \mathrm{kg})$ & 11.69 & 13.23 & 13.3 \\
\hline$(\%)$ & 89.44 & 89.55 & 89.59 \\
\hline
\end{tabular}

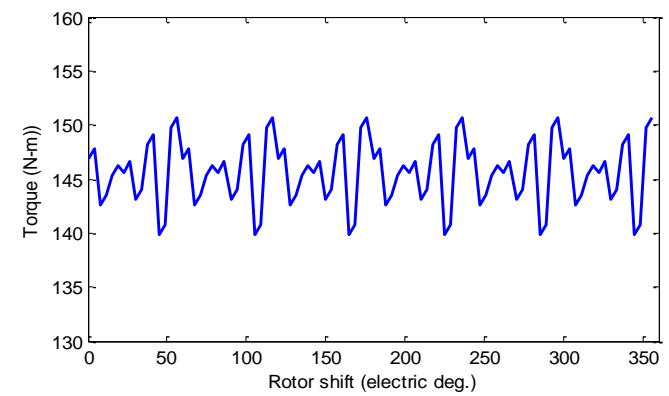

Fig. 4. Torque distributions from the magnetic circuit model

\subsection{Finite element refinement and verification}

Tooth shoes were designed to make a smooth magnetic flux distribution, thus reducing torque ripples. However, a small slot opening may cause a large leakage inductance so that the motor time constant may become large. On the other hand, tooth shoes may cause the winding task difficult so that the automatic machine winding may be impossible and the slot-fill ratio may not be improved. After shaping the stator teeth without shoes, it was found that the average torque changed very little, but the torque ripple was increased dramatically, as shown in Table 5. Nevertheless, the torque density was increased because of less weight without shoes.

It is well known that skewing the slots or magnets is able to reduce torque ripples [10]. Fig. 5 shows that the minimum torque ripple happens as the skew angle of stator teeth is about $1.6^{\circ}$, although the average torque is reduced from 131 to $124 \mathrm{Nm}$. The resulting back EMF distribution and its harmonics are illustrated in Fig. 6. The flux density distribution at the rated phase current from the finite element analysis is illustrated in Fig. 7.

Table 5. Finite Element Refinement Results

\begin{tabular}{|lr|c|c|c|}
\hline Performance & $\begin{array}{c}\text { Magnetic } \\
\text { circuit } \\
\text { model }\end{array}$ & $\begin{array}{c}\text { FEM } \\
\text { without } \\
\text { shoes }\end{array}$ & $\begin{array}{c}\text { FEM with } \\
\text { skew angle } \\
\text { of } 1.6^{\circ}\end{array}$ \\
\hline$T_{\text {avg }}(\mathrm{Nm})$ & 145 & 131 & 124 \\
\hline$T_{p} \quad(\%)$ & 7.4 & 42 & 8.4 \\
\hline$W$ & $(\mathrm{~kg})$ & 8.64 & 7.58 & 7.58 \\
\hline \multicolumn{2}{|l|}{$T_{d}(\mathrm{Nm} / \mathrm{kg})$} & 16.8 & 17.3 & 16.4 \\
\hline$\eta$ & $(\%)$ & 89.7 & 88.8 & 88.2 \\
\hline
\end{tabular}
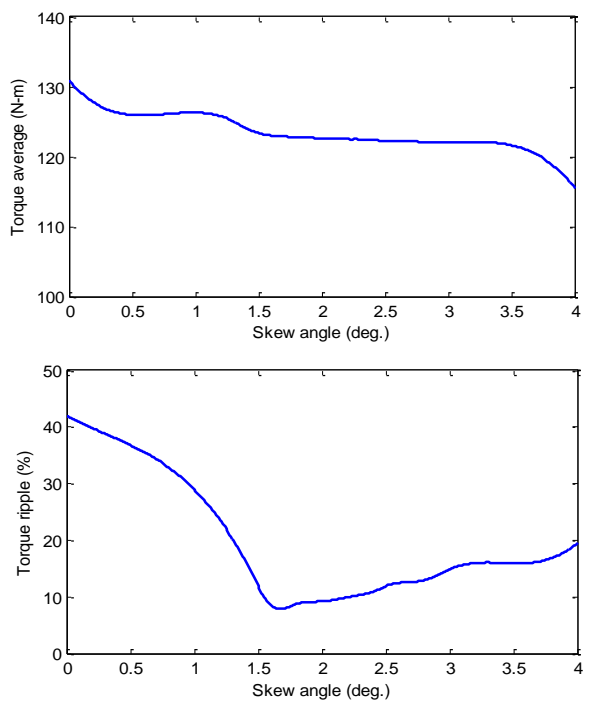

Fig. 5. Torque and torque ripple versus skew angle
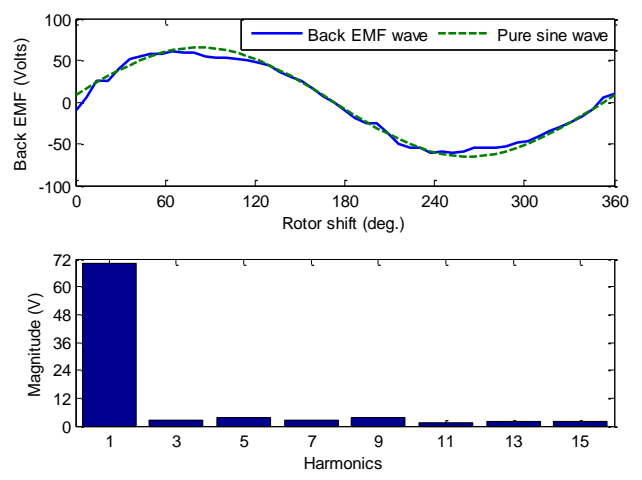

Fig. 6. Back EMF and its harmonics by the FEA

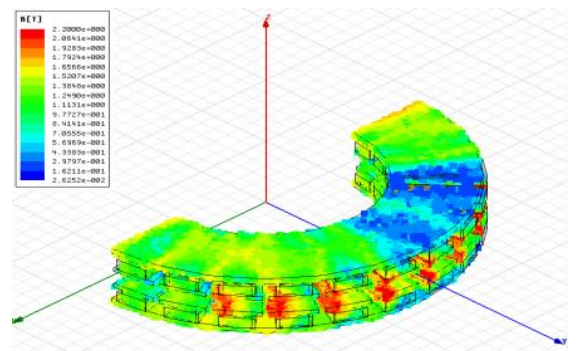

Fig. 7. Flux density distribution of a half motor 


\subsection{Axial attraction force}

Huge axial attractive force was found between the stator and rotor because high magnetic flux density in the air gap. Fig. 8(a) shows that the axial force distribution exerted on the stator for an electric period without current excitation when the air gap length is $0.5 \mathrm{~mm}$, and its average is over $11 \mathrm{kN}$. However, the rotor, which is sandwiched by two stators, will be attracted by the nearly balanced but oscillatory axial force, as shown in Fig. 8(b), where the peak axial force is about $100 \mathrm{~N}$. This attrative axial force may induce undesired vibration and noise, and the huge attractive axial force may cuase serious deformation on the stator and its housing. It is therefore necessary for engineers to design a stiff housing for the motor and pay much attention to the assembly of stator and its housing.

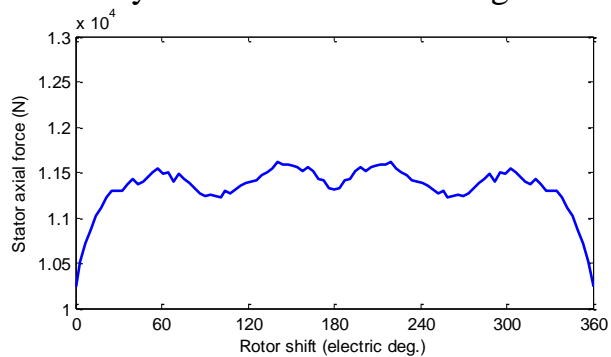

(a)

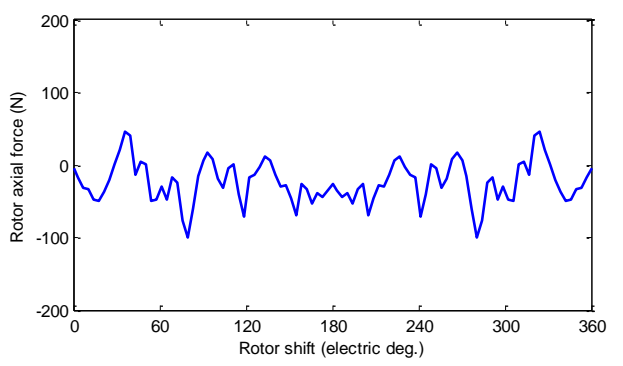

(b)

Fig. 8. Axial attractive force distribution (a) on the stator and (b) on the rotor for an electric period

\subsection{D- and Q-axis inductances}

Motor inductance tells how much flux linkage to phase windings is produced per unit ampere, and it will provide enough information for estimating the maximum torque produced by the minimum current. The $d$ - and $q$-axis inductances can be obtained by following equations

$$
\begin{gathered}
L_{d}\left(i_{d}, i_{q}\right)=\frac{\lambda_{d}\left(i_{d}, i_{q}\right)-\lambda_{m}}{i_{d}} \\
L_{q}\left(i_{d}, i_{q}\right)=\frac{\lambda_{q}\left(i_{d}, i_{q}\right)}{i_{q}}
\end{gathered}
$$

where $\lambda_{d}$ and $\lambda_{q}$ represent, respectively, the flux linkage of stator windings in the $d$ - and $q$-axis, while $i_{d}$ and $i_{q}$ are, respectively, the stator current components in the $d$-and $q$-axis. The magnet flux linkage $\lambda_{m}$ is calculated by letting $i_{d}=0$ and $\lambda_{m}=\lambda_{d}$ $\left(i_{d}=0, i_{q}\right)$, as shown in Fig. 9.

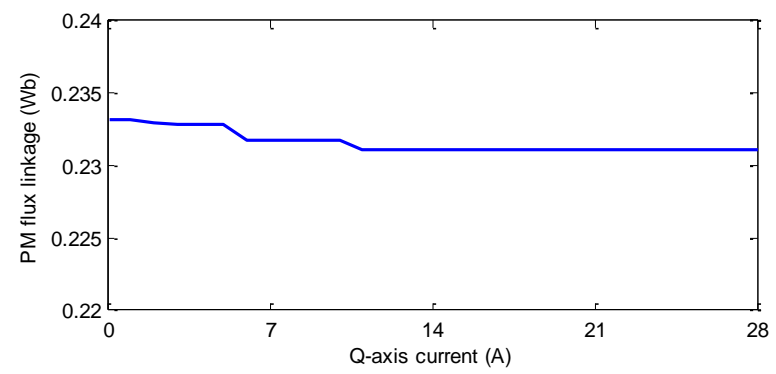

Fig. 9. Equivalent PM flux linkage

When the stator windings of each phase are connected in series, the motor produces higher torque but lower speed than the phase windings connected in parallel. The serial winding configuration becomes a low-speed gear or, namely, gearshift 1 , while the parallel winding configuration is a high-speed gear or gearshift 2 , as shown in Fig. 10. The $d$ - and $q$-axis inductances for gearshifts 1 and 2 for various $d$ - and $q$-axis current components are illustrated in Fig. 11.

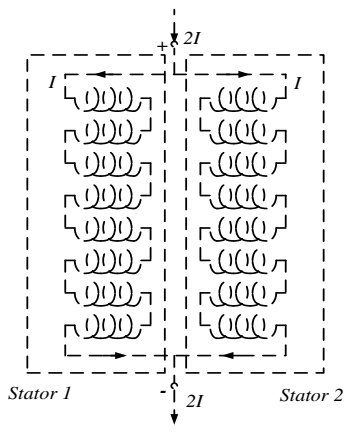

(a)

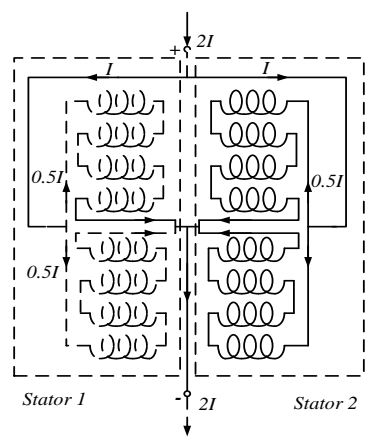

(b)
Fig. 10. Scheme of (a) gearshift 1 and (b) gearshift 2

\section{Estimation of Torque and Power versus Speed Curves}

Since the AFPM motor configuration belongs to the class of surface-mounted permanent magnet (SPM) motors, the $q$-axis inductance is close to but a little larger than the $d$-axis inductance. The reluctance torque plays a minor role for extending the torque and speed range, however, the MTPA theory is still worth estimating the torque and power versus speed curves.

First, the torque production is expressed by

$$
T=(3 / 4) N_{m}\left\lfloor\lambda_{m} i_{q}+\left(L_{d}-L_{q}\right) i_{d} i_{q}\right\rfloor
$$

When the maximum current $i_{\max }$ is applied, the $d$ and $q$-axis current components can be expressed as $i_{d}=i_{\max } \cos \beta$ and $i_{q}=i_{\max } \sin \beta$, where $\beta$ is the phase 
angle between the $d$ - and $q$-axis current components. Therefore, the optimal phase angle that maximizes the torque production (18) is obtained by

$$
\beta_{o p t}=\cos ^{-1}\left[\frac{-\lambda_{m}+\sqrt{8 i_{\max }^{2}\left(L_{d}-L_{q}\right)^{2}}}{4 i_{\max }\left(L_{d}-L_{q}\right)}\right]
$$

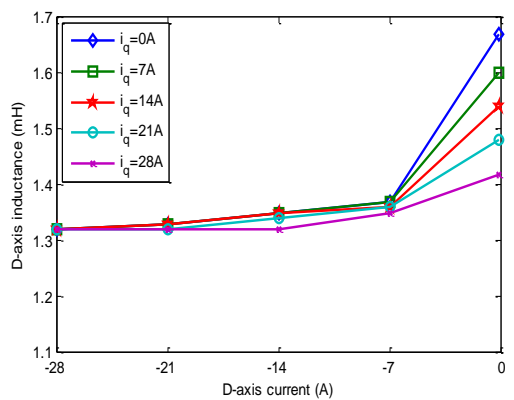

(a)

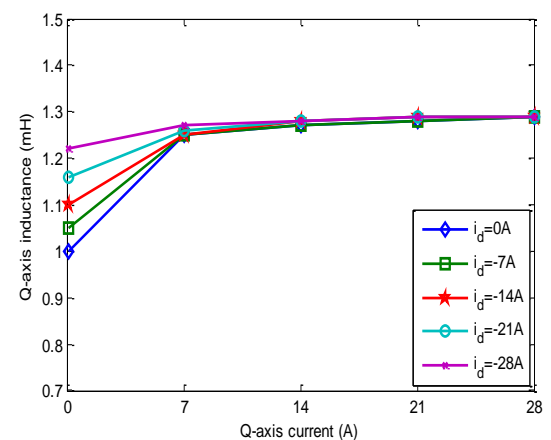

(b)

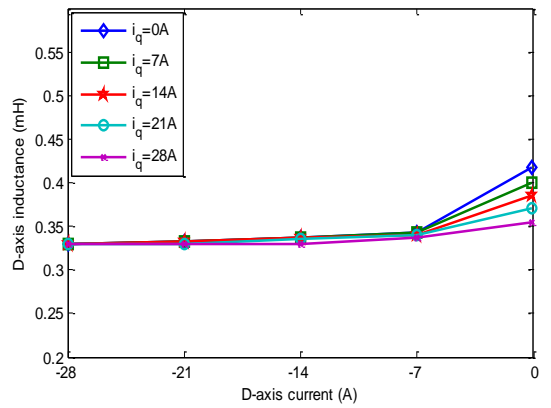

(c)

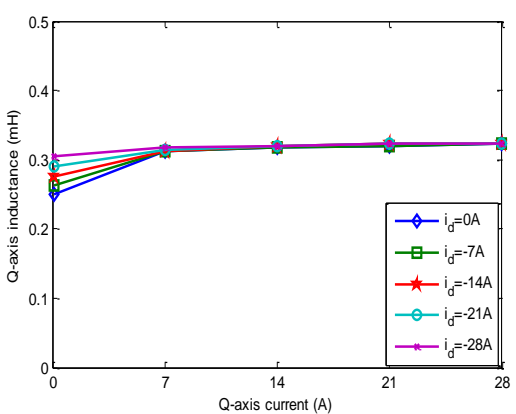

(d)

Fig. 11. (a) $D$ - and (b) $q$-axis inductances of gearshift 1 , (c) $d$ - and (d) $q$-axis inductances of gearshift 2 for various $d$ - and $q$-axis current components
The maximum torque and the corresponding $d$-axis current become

$$
T_{\max }=\frac{3}{4} N_{m} i_{q}\left[\frac{3}{4} \lambda_{m}+\frac{1}{4} \sqrt{\lambda_{m}^{2}+8 i_{\max }^{2}\left(L_{d}-L_{q}\right)^{2}}\right]
$$

and

$$
i_{d}=\frac{-\lambda_{m}}{4\left(L_{d}-L_{q}\right)}+\frac{1}{4} \sqrt{\left(\frac{\lambda_{m}}{L_{d}-L_{q}}\right)^{2}+8 i_{\max }^{2}}
$$

By ignoring the phase resistance, the motor speed can be calculated under the limit of supplied voltage $V_{\max }$ as

$$
\omega=\frac{V_{\max }}{\sqrt{L_{q}^{2} i_{q}^{2}+\left(L_{d} i_{d}+\lambda_{m}\right)^{2}}} .
$$

The maximum speed in the constant torque region is then obtained by substituting the optimal $i_{d-o p t}$ $=i_{\text {max }} \cos \beta_{\text {opt }}$ and $i_{q-o p t}=i_{\text {max }} \sin \beta_{\text {opt }}$ to (22). In the field-weakening operation region, the torque and speed can be obtained from (18) and (22) by letting $i_{q}=i_{q-o p t}-k \Delta i_{q}$ and $i_{d}=-\sqrt{i_{\max }^{2}-i_{q}^{2}}$, where $\Delta i_{q}$ is an increment of current and $k$ is an integer. Fig. 12 shows the resulting torque and power versus speed curves for different gearshifts and their corresponding current phase angles that produce the maximum torque per ampere.

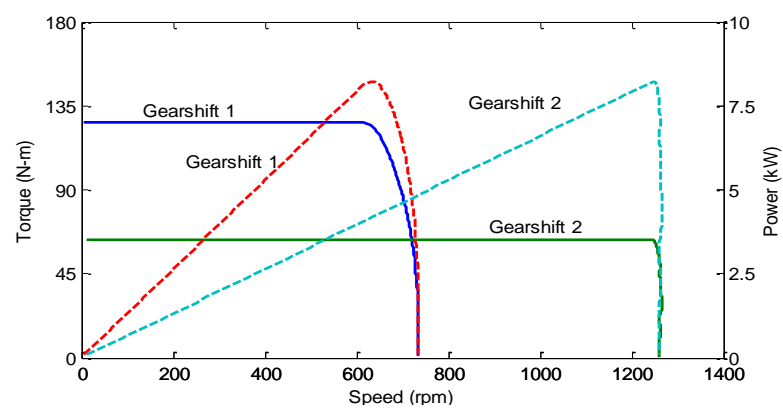

(a)

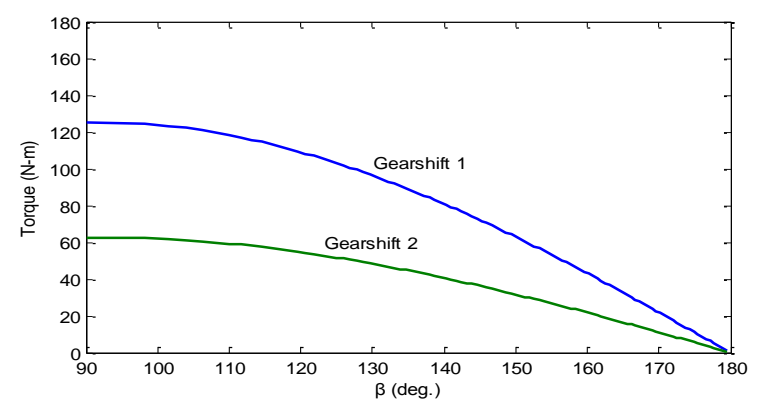

(b)

Fig. 12. (a) Torque and power versus speed curves and (b) the corresponding optimal current phase angles for different gearshifts 


\section{Conclusions}

This paper has proposed a systematic approach for the design of a high torque density AFPM wheel motor for light electric vehicles. The design procedure started from a preliminary design to choose the numbers of slots and poles and the winding configuration. The multifunctional optimal design with magnetic circuit models was then performed to determine an optimal shape of the wheel motor. Finally, the optimal shape was verified and refined by the finite element analysis. The resulting wheel motor has a maximum torque of $124 \mathrm{Nm}$, torque density of $16.4 \mathrm{Nm} / \mathrm{kg}$ with active materials, and the maximum output power at $8 \mathrm{~kW}$. Although the motor $d$ - and $q$-axis inductances differ insignificantly due to the configuration of SPM, the maximum torque per ampere theory is still applied to estimate the torque and power versus speed curves, where the corresponding current phase angles are obtained. These curves will be very useful for efficiently controlling the proposed wheel motor. Two prototype wheel motors are fabricated, and will be installed on two rear wheels of an LEV after a standard performance test.

\section{Acknowledgments}

This work was supported by the National Science Council of Taiwan, ROC, under contract NSC982221-E-002-184-MY3.

\section{References}

[1] C. C. Chan, A. Bouscayrol, and K. Y. Chen, "Electric, hybrid, and fuel-cell vehicles: architectures and modeling," IEEE Transactions on Vehicular Technology, vol. 59, pp. 589-598, Feb. 2010.

[2] D. Carney, "Motors play important EV roles," Automotive Engineering International, vol. 116, no. 7, pp.20-23, July 2008.

[3] M. Zeraoulia, M. E. h. Benbouzid, and D. Diallo, "Electric motor drive selection issues for HEV propulsion systems: a comparative study," IEEE Transactions on Vehicular Technology, vol. 55, no. 6, pp. 1756-1764, Nov. 2006.

[4] Z. Q. Zhu and D. Howe, "Electrical machines and drives for electric, hybrid, and fuel cell vehicles," Proceedings of the IEEE, vol. 95, no. 4, pp. 746-765, April 2007.

[5] F. Magnussen and C. Sadarangani, "Winding factors and Joule losses of permanent magnet machines with concentrated windings," IEEE International Conference of Electric Machines and Drives, Madison, Wisconsin, vol. 1, pp. 333-339, June 1-4, 2003.
[6] A. M. El-Refaie, "Fractional-slot concentratedwindings synchronous permanent magnet machines: opportunities and challenges," IEEE Transactions on Industrial Electronics, vol. 57, pp. 107-121, Jan. 2010.

[7] V. Ostovic, Computer-Aided Analysis of Electric Machines, Prentice Hall, 1994.

[8] Y. P. Yang, Y. P. Luh, and C. H. Cheung, "Design and control of axial-flux brushless DC wheel motors for electric vehicles - Part I: Multiobjective optimal design and analysis," IEEE Transactions on Magnetics, vol. 40, pp. 1873-1882, Jul 2004.

[9] Z. Q. Zhu and D. Howe, "Influence of design parameters on cogging torque in permanent magnet machines," IEEE Transactions on Energy Conversion, vol. 15, pp. 407-412, Dec. 2000.

[10] D. Hanselman, Brushless Permanent Magnet Motor Design, 2nd ed, 2003.

\section{Authors}

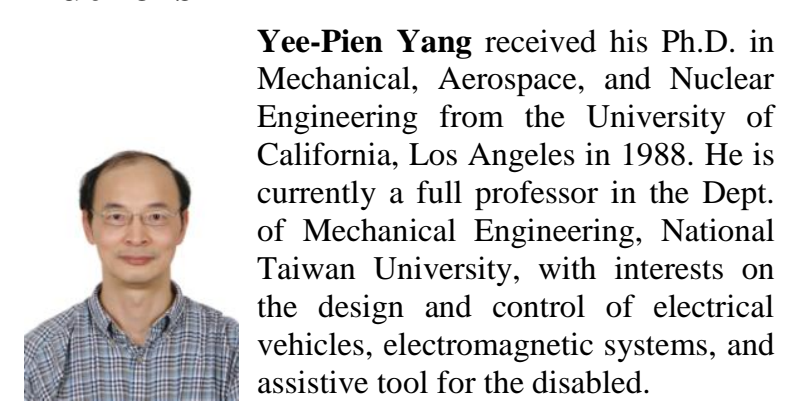

Chung-Han Lee received both his BS and MS from the Department of Mechanical Engineering of National

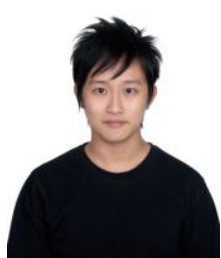
Taiwan University in 2008 and 2010, respectively. $\mathrm{He}$ is currently in the military service, and his research interests are on the design and control of electrical machines and electrical vehicles. 